\title{
Utjecaj različitog tipa umjetnog osvjetljenja na klijavost sjemena matovilca i kres salate
}

\section{Sažetak}

Cilj rada je bio utvrditi utjecaj LED (Light Emitting Diodes) i FLUO (fluorescentno svjetlo) osvjetljenja na klijavost $i$ energiju klijanja sjemena te masu i visinu klijanaca matovilca i kres salate. Sjetva naturalnog sjemena provedena je u Petrijeve zdjelice u komori opremljenoj LED i FLUO lampama. LED lampe su bile opremljene crvenim (650-670 nm) i plavim (440-460 nm) LED diodama u omjeru 3:1. Istraživanje je provedeno u Laboratoriju za povrćarstvo, cvjećarstvo, ljekovito i začinsko bilje Poljoprivrednog fakulteta u Osijeku. Utvrđen je statistički opravdan utjecaj tipa osvjetljenja na energiju klijanja i klijavost sjemena matovilca, a veće vrijednosti utvrđene su uslijed primjene LED lampi. Suprotno, pod FLUO lampama je utvrđena značajno veća masa i visina klijanaca matovilca te visina klijanaca kres salate. Međutim, tip osvjetljenja nije značajno utjecao na klijavost i energiju klijanja te masu klijanaca kres salate. Prema tome, može se zaključiti da je odgovor na tip osvjetljenja uvjetovan biljnom vrstom već od samih početaka rasta i razvoja.

Ključne riječi: Valerianella locusta L., Lepidium sativum L., LED lampe, FLUO lampe, klijavost

\section{Uvod}

Matovilac (Valerianella locusta L.) je jednogodišnja biljna vrsta iz porodice Valerianaceae, a kres salata (Lepidium sativum L.) je dvogodišnja biljna vrsta iz porodice Brassicaceae. lako su iz različitih porodica, obje vrste imaju vrlo slične zahtjeve prema agroekološkim uvjetima tijekom proizvodnje. Biljke su dugog dana, podnose niske temperature tijekom rasta i razvoja te su otporne na kratkotrajni mraz (Lešić i sur., 2002). Međutim, svjetlost je jedan od najvažnijih abiotskih čimbenika tijekom uzgoja svih biljnih vrsta jer utječe na rast i razvoj od trenutka nicanja. Svjetlost utječe na djelovanje citokroma, fotoperiodizam, prekid dormantnosti, cvatnju te mnoge druge fiziološki uvjetovane procese (Ologundudu i sur., 2013.). Iz ovih razloga su davno započela istraživanja o utjecaju različitih tipova umjetnog osvjetljenja na poboljšanje stope rasta i razvoja te povećanja prinosa pojedinih biljnih vrsta. Kod proizvodnje presadnica koje se uzgajaju uglavnom u zaštićenim prostorima, bitno je održavati ravnotežu između optimalne temperature i osvjetljenja kako ne bi došlo do njihovog izduživanja što nepovoljno djeluje u svim kasnijim fazama rasta i razvoja. U zaštićenim prostorima za tu svrhu se koriste različite tipovi osvjetljenja kao što su fluorescentne lampe, HPS (High Pressure Sodium) lampe, a u novije vrijeme i LED (Light Emitting Diodes) lampe s diodama različitih valnih duljina. LED lampe imaju različite uloge u hortikulturi, uključujući kontrolirana istraživanja okolišnih faktora, rasvjetu $\mathrm{u}$ in vitro multiplikaciji te umjetnu rasvjetu u staklenicima i plastenicima tijekom proizvodnje presadnica (Morrow, 2008). U prednosti LED lampi se ubrajaju, a u odnosu na ostale izvore svjetlosti, mogućnost upravljanja valnim duljinama tj. spektralnim sastavom izvora svjetlosti kao i sposobnost proizvodnje vrlo visoke razine osvjetljenja s niskom razinom radijacije (Morrow, 2008). Bula i sur. (1991) navode da su u proizvodnji salate LED lampe jednako dobre kao i flu- 
orescentne lampe.

Učinak LED rasvjete je istraživan i u vrlo ranim fazama rasta i razvoja biljaka. U istraživanju Behzadi i sur. (2012) utvrđeno je pozitivno djelovanje tretmana sjemena bosiljka s crvenim LED diodama što se očitovalo u povećanju klijavosti sjemena i uravnoteženim rastom i razvojem klijanaca. Također, utvrđeno je da primjena crvenih te kombinacije crvenih i plavih LED dioda pozitivno utječe na rast klijanaca i klijavost sjemena maslačka. Istovremeno, biljke maslačka osvijetljene crvenim LED diodama $(660 \mathrm{~nm})$ imale su značajno veću koncentraciju antocijanina u lišću (Ryu i sur., 2012).

U istraživanju Stutte i sur. (2009.) došlo je do značajnog povećanja ukupne biomase i elongacije lista crvenolisne salate pod utjecajem LED dioda daleko crvenog spektra svjetlosti. $U$ istom istraživanju je utvrđeno da primjena LED dioda plavog spektra djeluje na povećanje koncentracije bioprotektivnih komponenata te je istovremeno došlo do značajnog porasta prinosa.

Mizuno i sur. (2011.) istraživali su utjecaj plavih LED dioda na presadnice kupusa sorti 'Kinshun' i 'Red Rookie'. Utvrdili su značajan utjecaj plavih LED dioda na elongaciju peteljki kod obje sorte te je istovremeno došlo do povećanja sadržaja klorofila kod zeleno-lisne sorte 'Kinshun'.

Iz svega navedenoga je očito da tip osvjetljenja ima različit utjecaj na rast i razvoj biljke ovisno o biljnoj vrsti pa je cilj ovog istraživanja bio odrediti klijavost, energiju klijanja sjemena te masu i visinu klijanaca matovilca i kres salate pod utjecajem FLUO i LED osvjetljenja.

\section{Materijali i metode}

Istraživanje je provedeno tijekom ožujka 2017. godine u walk-in klima komori u laboratoriju za Povrćarstvo, cvjećarstvo, ljekovito i začinsko bilje Poljoprivrednog fakulteta u Osijeku. U istraživanju je korišteno naturalno sjeme matovilca i kres salate. Prema deklaraciji na pakiranju, sjeme matovilca je imalo 90 \%-tnu klijavost i 98 \%-tnu čistoću, a sjeme kres salate $85 \%$-tnu klijavost te 98 \%-tnu čistoću. Sjeme je postavljeno na naklijavanje 22. ožujka 2017. godine. Prilikom postavljanja pokusa, sjeme obje vrste je posijano u Petrijeve zdjelice u 4 ponavljanja po 50 sjemenki. Sjeme je posijano na sterilnu pamučnu vatu koja je natopljena vodom i postavljeno ispod LED i FLUO lampi istovremeno. Standardna metoda za ispitivanje klijavosti sjemena kod obje vrste je modificirana prema rezultatima preliminarnog ispitivanja klijavosti sjemena gdje je uočeno propadanje klijanaca matovilca nakon 10 dana tj. kres salate nakon 8 dana. Temperatura u komori je bila $20^{\circ} \mathrm{C}$ što predstavlja optimalnu temperaturu ispitivanja klijavosti za obje vrste, a osvjetljenje je bilo postavljeno na dnevno-noćni režim rada u omjeru 16:8 sati. Po četiri Petrijeve zdjelice od obje vrste su bile postavljene ispod LED lampi, dok su po četiri zdjelice bile smještene ispod FLUO lampi. LED lampe su opremljene plavim (440-460 $\mathrm{nm}$ ) i crvenim diodama (650-670 nm) u omjeru 3:1. Jačina svjetlosti u razini Petrijevih zdjelica je kod oba izvora svjetlosti iznosila približno 8000 luksa budući da se visina polica može prilagođavati u odnosu na izvor svjetlosti kao i jačina LED lampi pomoću potenciometra. Jačina svjetlosti je izmjerena pomoću luksometra Voltcraft MS-200 LED. Tijekom istraživanja je po potrebi dodana voda. Energija klijanja izmjerena je 26. ožujka, a 30. ožujka je ispitivanje završeno te je izmjerena klijavost, visina i prosječna masa klijanaca. Masa klijanaca je utvrđena pomoću laboratorijske vage (Kern \& Sohn) vaganjem svih klijanaca te izračunavanjem prosječne mase po jednom klijancu.

Podatci su statistički obrađeni jednosmjernom analizom varijance koristeći programski paket SAS 9.1. (SAS Institute Inc., New York) i Microsoft Excel 2016. Razlike istraživanih pokazatelja pod utjecajem tipa osvjetljenja su testirane pomoću Fisher-ovog LSD testa na razini signifikantnosti 0,05 . 


\section{Rezultati i rasprava}

Kod matovilca je nakon statističke obrade podataka utvrđen značajan utjecaj tipa osvjetljenja na visinu klijanaca. Značajno veća $(p=0,05)$ visina je izmjerena kod klijanaca koji su bili pod FLUO lampama (Grafikon 1).

Također, značajno veća masa klijanaca matovilca $(p=0,05)$ je izmjerena pod FLUO lampama (Grafikon 2). Isto kao kod matovilca, klijanci kres salate su bili značajno viši $(p=0,05)$ pod FLUO lampama (Grafikon 1). Međutim, tip osvjetljenja nije značajno utjecao na masu klijanaca kres salate te nije bilo značajne razlike u masi klijanaca pod FLUO lampama u usporedbi s klijancima pod LED lampama (Grafikon 2).

Za razliku od visine i mase klijanaca matovilca, energija klijanja i klijavost je bila značajno veća $(p=0,05)$ kod sjemena matovilca koje je bilo pod LED lampama (Grafikon 3 ).

Klijavost i energija klijanja sjemena kres salate nisu se razlikovali s obzirom na tip osvjetljenja. Prema tome, nije bilo statističke značajne razlike u klijavosti sjemena kres salate pod FLUO lampama u usporedbi s klijavošću koje je utvrđeno pod LED lampama (Grafikon 4). Također, nije bilo statističke značajne razlike u energiji klijanja sjemena pod FLUO lampama u usporedbi s energijom klijanja sjemena utvrđenoj pod LED lampama (Grafikon 4).

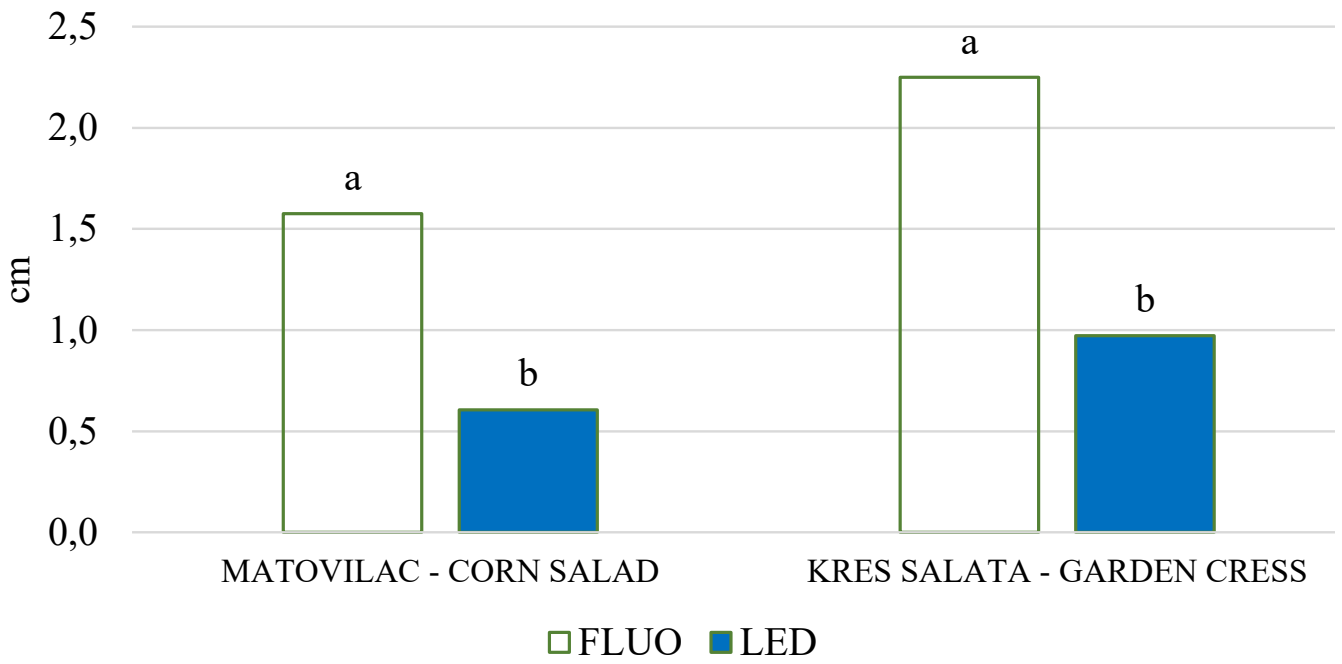

Grafikon 1. Utjecaj LED i FLUO osvjetljenja na visinu klijanaca matovilca i kres salate. Vrijednosti obilježene s različitim slovima ${ }^{a, b}$ se značajno razlikuju prema LSD testu; $p=0,05$.

Figure 1. Influence of LED and FLUO lighting on corn salad and garden cress seedlings height. Values marked with different letters ${ }^{\mathrm{a}, \mathrm{b}}$ significantly differs according to LSD test; $\mathrm{p}=0.05$. 


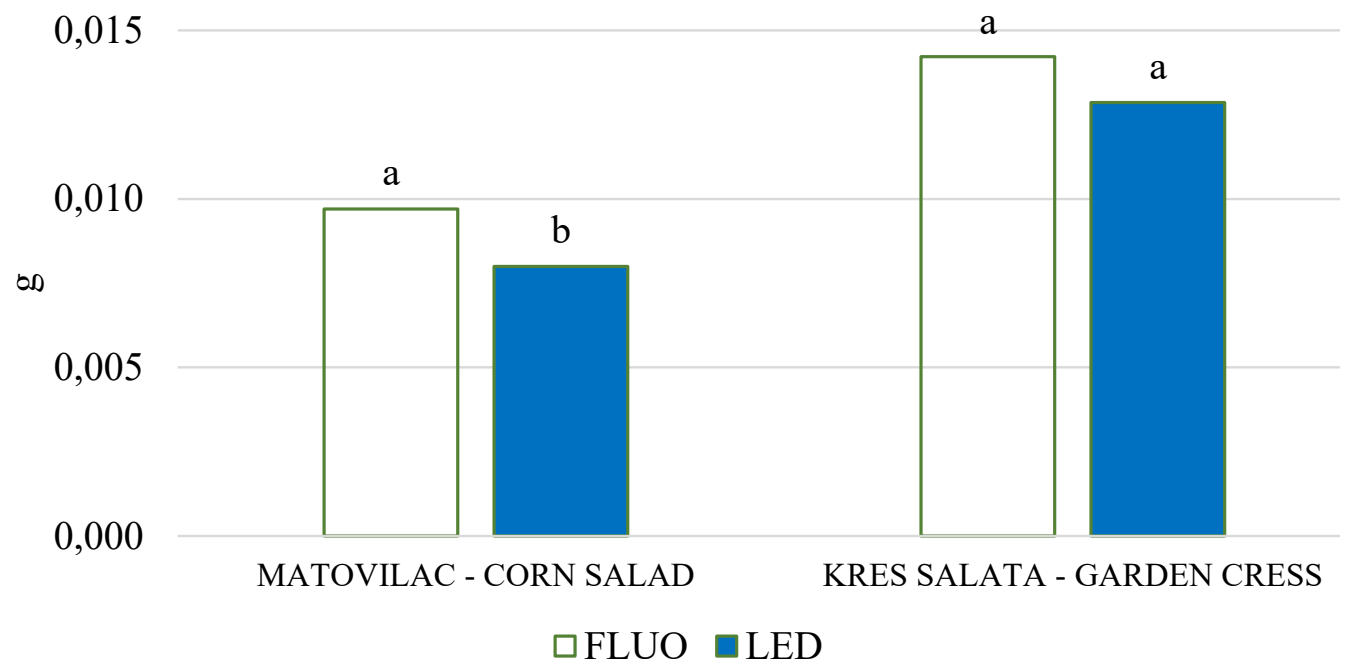

Grafikon 2. Utjecaj LED i FLUO osvjetljenja na masu klijanaca matovilca. Vrijednosti obilježene $s$ različitim slovima a,b se značajno razlikuju prema LSD testu; $p=0,05$.

Figure 2. Influence of LED and FLUO lighting on corn salad seedlings fresh weight. Values marked with different letters ${ }^{a, b}$ significantly differs according to LSD test; $p=0.05$.

85

a

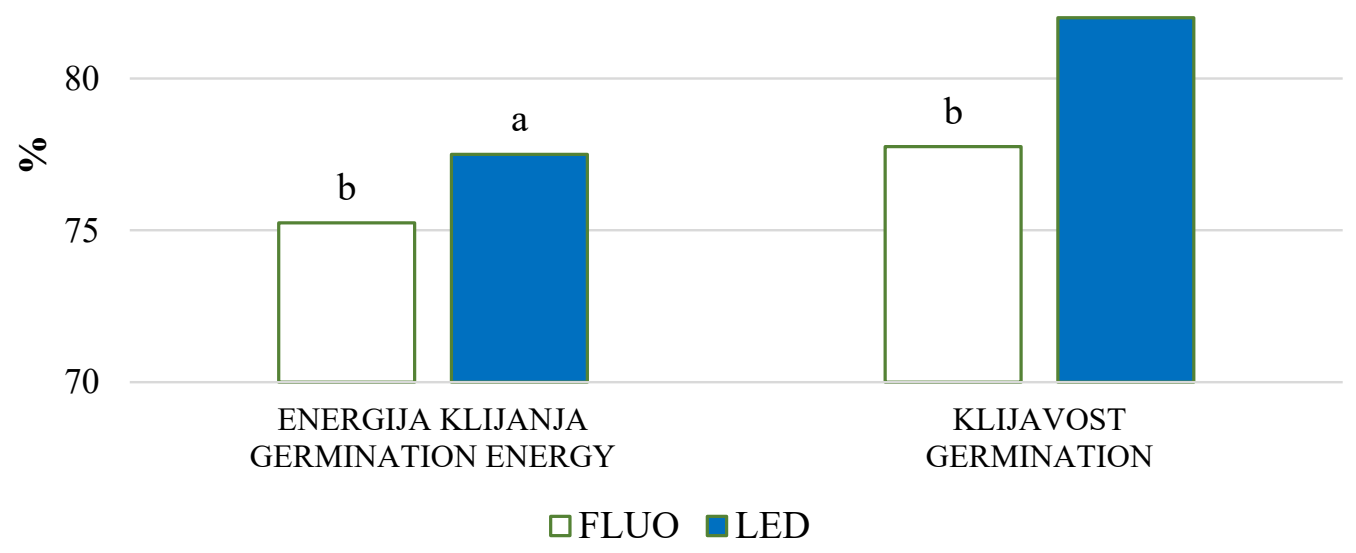

Grafikon 3. Utjecaj LED i FLUO osvjetljenja na energiju klijanja i klijavost sjemena matovilca. Vrijednosti obilježene $s$ različitim slovima a,b se značajno razlikuju prema LSD testu; $p=0,05$.

Figure 3. Influence of LED and FLUO lighting on corn salad seed germination and germination energy. Values marked with different letters $a, b$ significantly differs according to LSD test; $\mathrm{p}=0.05$. 
85

80

a

$$
e^{e}
$$

75

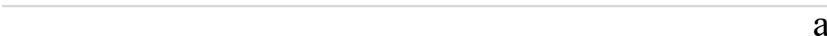

$\circ$

70

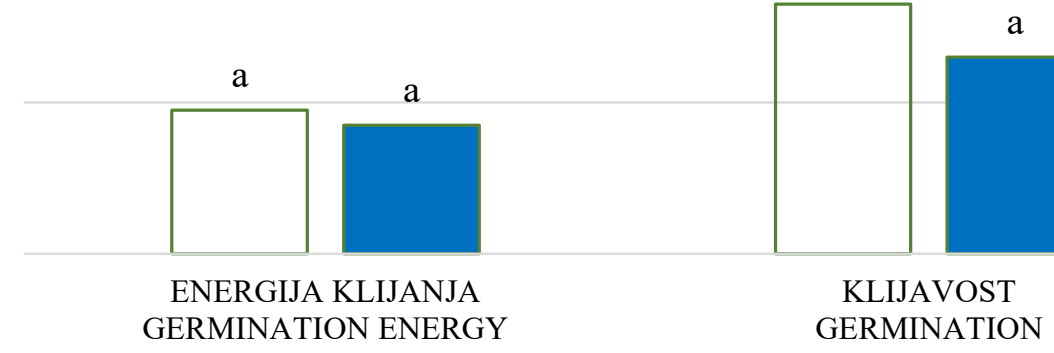

$\square$ FLUO $\square$ LED

Grafikon 4. Utjecaj LED i FLUO osvjetljenja na energiju klijanja i klijavost sjemena kres salate. Vrijednosti obilježene $s$ istim slovom a se ne razlikuju značajno prema LSD testu; $p=0,05$.

Figure 4. Influence of LED and FLUO lighting on garden cress seed germination and germination energy. Values marked with same letter a do not differ significantly according to LSD test; $p=0.05$.

U ovom istraživanju je utvrđeno da različite biljne vrste, $i$ to matovilac $i$ kres salata, različito reagiraju na specifičan tip osvjetljenja od samog početka rasta i razvoja.

Olle i Viršile (2013.) su u svom preglednom radu prikazali utjecaj LED rasvjete na intenzitet fotosinteze, kvalitetu plodova te prinos rajčice, paprike i krastavaca te rast i razvoj lisnatih vrsta povrća. Također, u ovom je radu prikazan utjecaj kombinacija LED, FLUO i HPS lampi te prirodnog osvjetljenja. Iz rezultata različitih istraživanja je zaključeno da su crveni i plavi spektar važni za rast zelenog lisnatog povrća, rajčice, krastavca i paprike, no ipak i teorijski neprofitabilni dio spektra, kao što su žuti i zeleni, značajno utječu na fiziološke procese različitih biljnih vrsta. Odgovor na tip osvjetljenja je uvjetovan biljnom vrstom što potvrđuju i istraživanja Astolfi i sur. (2012.) gdje je ispitan utjecaj LED i FLUO osvjetljenja na rast sadnica bukve, trešnje i hrasta. U njihovom istraživanju LED lampe su bile opremljene kombinacijom dioda plavog, zelenog, crvenog i daleko crvenog spektra svjetlosti. Utvrdili su da su sadnice ukupno 27 drvenastih vrsta, pogotovo kod bukve, pod LED lampama imale značajno veću svježu i suhu masu, visinu izboja te lisnu površinu u usporedbi s FLUO lampama. Također, kod istih vrsta je zabilježena niža koncentracija klorofila kod LED lampi. Suprotno, iako koncentracija klorofila nije mjerena, u ovom istraživanju je opaženo da su klijanci kres salate pod LED lampama bili intenzivnije zelene boje što može biti znak veće koncentracije klorofila te su istovremeno bili značajno niži (Slika 1). Klijavost i energija klijanja sjemena matovilca su u ovom istraživanju bili značajno veći pod LED lampama što nije iznenađujuće jer je ranije opisano da crvena svjetlost potiče klijavost i fotomorfogene odgovore biljaka (Hogewoning i sur., 2010; Sager i McFarlane, 1997).

S obzirom na visinu klijanaca, kod obje vrste su izmjereni niži klijanci pod LED lampama, dok se masa klijanaca kod kres salate nije razlikovala u ovisnosti o tipu svjetlosti što upućuje na mogućnost pojačanog rasta i razvoja klicinog korjenčića. Treba naglasiti da u ovom istraživanju nije bilo mogućnosti mjerenja dužine klicinog korjenčića jer je urastao u pamučnu vatu te se nije mogao pravilno uzorkovati. 


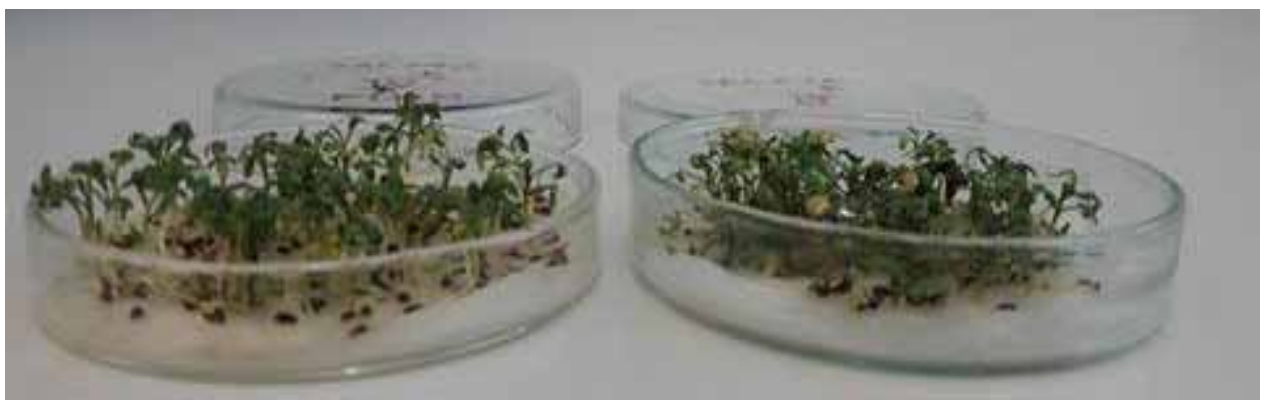

Slika 1. Klijanci kres salate na dan testiranja (FLUO-lijeva strana; LED-desna strana)

Picture 1. Garden cress seedlings on testing day (FLUO-left side; LED-right side)

Pojedina istraživanja upućuju na pozitivne učinke LED lampi na rast i razvoj korijena kao u istraživanju Li i sur. (2013) gdje je utvrđeno da su klijanci uljane repice imali duži korijen pod LED lampama s istim omjerom plavih i crvenih dioda (3:1) kao i lampe korištene u ovom istraživanju. Također, u istraživanju Li i sur. (2013) je pod LED lampama utvrđena i ukupna veća biomasa uljane repice $u$ usporedbi $s$ ukupnom biomasom uljane repice uzgajane pod FLUO lampama. Suprotno, kod salate je utvrđena veća suha masa korijena kod biljaka koje su bile osvjetljene s FLUO lampama u usporedbi s LED lampama opremljenim s crvenim, plavim ili kombinacijom crvenih i plavih dioda u omjeru 1:1 (Chen i sur., 2014), a isto je potvrđeno i u hidroponskom uzgoju salate (Lin i sur., 2013). Nadalje, kod krizanteme se povećava ukupna produkcija biomase pod LED lampama s većim omjerom plavih dioda dok se kod ruže akumulira više suhe tvari u cijeloj biljci u slučaju osvjetljenja s LED lampama s većim omjerom crvenih dioda (Ouzounis i sur., 2014). Kod rajčice je pak utvrđeno da umjetno osvjetljenje s LED lampama povećava masu ploda i ukupan prinos (Vinković i sur., 2016). Različite valne duljine svjetlosti utječu, ne samo na rast i razvoj biljke, nego i na koncentraciju bioaktivnih komponenata kao što su fenolni spojevi. Tako je u istraživanju Bantis i sur. (2016) utvrđena veća koncentracija polifenola u klijancima bosiljka pod lampama s različitim kombinacijama dioda plavog, crvenog i daleko crvenog spektra svjetlosti. Na kraju, istraživanja o osvjetljenju traju već dva desetljeća, no još uvijek nisu otkrivene kombinacije specifičnog spektra za različite biljne vrste kako bi se postigla maksimalna produktivnost i ukupna produkcija biomase.

\section{Zaključak}

Tijekom ovog istraživanja je utvrđen niz učinaka različitog tipa osvjetljenja na klijavost, energiju klijanja, masu i visinu klijanaca matovilca i kres salate. Iz opisanih rezultata slijedi da tip osvjetljenja značajno utječe na energiju klijanja sjemena matovilca koja je bila značajno veća pod LED lampama, dok energija klijanja sjemena kres salate nije ovisila o tipu osvjetljenja. Također, tip osvjetljenja značajno utječe na klijavost sjemena matovilca koja je bila značajno veća pod LED lampama, dok klijavost sjemena kres salate nije bila pod značajnim utjecajem tipa osvjetljenja. Nadalje, značajno veća masa klijanaca matovilca je izmjerena pod FLUO lampama dok je utjecaj tipa osvjetljenja na masu klijanaca kod kres salate izostao. Značajno viši klijanci obje vrste su izmjereni pod FLUO lampama. Iz navedenih rezultata se može zaključiti da je odgovor na tip osvjetljenja uvjetovan biljnom vrstom te su potrebna daljnja istraživanja kako bi se utvrdili mogući razlozi različitih odgovora matovilca i kres salate na FLUO i LED lampe koje su korištene u ovom istraživanju. Na kraju, bilo bi vrlo zanimljivo provesti istraživanja na ove dvije vrste tijekom dužeg vegetacijskog perioda te istražiti utjecaj na antioksidativnu aktivnost, promjenu enzimske aktivnosti, stopu rasta nadzemnih i podzemnih vegetativnih organa te ukupan prinos biomase. 


\title{
Zahvala
}

Zahvaljujemo se gospodinu Draganu Cerovcu, vlasniku tvrtke Elektronik Cerovac e.K. iz Brettena, Njemačka, na donaciji LED lampi koje su korištene tijekom ovoga istraživanja.

\section{Literatura}

Astolfi, S., Marianello, C., Grego, S., Bellarosa, R. (2012) Preliminary Investigation of LED Lighting as Growth Light for Seedlings from Different Tree Species in Growth Chambers. Notulae Botanicae Horti Agrobotanici, 40 (2), 31-38.

DOI: $10.15835 /$ nbha4028221

Bantis, F., Ouzounis, T., Radoglou, K. (2016) Artificial LED lighting enhances growth characteristics and total phenolic content of Ocimum basilicum, but variably affects transplant success. Scientia Horticulturae, 198, $277-283$.

DOI: 10.1016/j.scienta.2015.11.014

Behzadi, H.R., Qaryan, M., Shahi, S. (2012) The Influence of LED Light on Basil Seeds before Sowing and its Effects on Growing and Germination. International Journal of Plant Research, 2 (4), 108-110. DOI: 10.5923/j.plant.20120204.02

Bula, R.J., Morrow R.C., Tibbitts T.W., Barta D.J., Ignatius R.W. and Martin T.S. (1991) Light emitting diodes as a radiation source for plants. HortScience, 26, 203- 205.

Chen, X., Guo, W., Xue, X., Wang, L., Qiao, X. (2014) Growth and quality responses of 'Green Oak Leaf' lettuce as affected by monochromic or mixed radiation provided by fluorescent lamp (FL) and light-emitting diode (LED). Scientia Horticulturae 172, 168-175. DOI: 10.1016/j.scienta.2014.04.009

Hogewoning, S.W., Trouwborst, G., Maljaars, H., Poorter, H., van leperen, W., Harbinson, J. (2010) Blue light doseresponses of leaf photosynthesis, morphology, and chemical composition of Cucumis sativus grown under different combinations of red and blue light. Journal of Experimental Botany, 61, 3107-3117. DOl: 10.1093/jxb/erq132

Lešić, R., Borošić, J., Buturac, I., Custić, M., Poljak, M., Romić, D. (2002) Povrćarstvo. Cakovec: Zrinski d.d.

$\mathrm{Li}, \mathrm{H}$., Tang, C., Xu, Z. (2013) The effects of different light qualities on rapeseed (Brassica napus L.) plantlet growth and morphogenesis in vitro. Scientia Horticulturae, 150, 117-124. DOI: 10.1016/j.scienta.2012.10.009

Lin, K.-H., Huang, M.-Y., Huang, W.-D., Hsu, M.-H., Yang, Z.-W., Yang, C.-M. (2013) The effects of red, blue, and white light-emitting diodes on the growth, development, and edible quality of hydroponically grown lettuce (Lactuca sativa L. var. capitata). Scientia Horticulturae, 150, 86-91. DOI: 10.1016/j.scienta.2012.10.002

Mizuno, T., Amaki, W., Watanabe, H. (2011) Effect of monochromatic light irradiation on the growth and anthocyanin contents in leaves of cabbage seedlings. Acta Horticulturae, 907, 179-184. DOI: 10.17660/ActaHortic.2011.907.25 Morrow, R.C. (2008) LED lighting in horticulture. HortScience, 43, 1947-1950.

Ologundudu, A.F., Adelusi, A.A., Adekoya, K.P. (2013) Effect of Light Stress on Germination and Growth Parametres of Corchorus olitorius, Celosia argentea, Amaranthus cruentus, Abelmoschus esculentus and Delonix regia. Notulae Scientia Biologicae, 5 (4), 468-475. DOl: 10.15835/nsb549183

Olle, M., Viršilè, A. (2013) The effects of light-emitting diode lighting on greenhouse plant growth and quality. Agricultural and Food Science, 22, 223-234.

Ouzounis, T., Fretté, X., Rosenqvist, E., Ottosen, C.-O. (2014) Spectral effects of supplementary lighting on the secondary metabolites in roses, chrysanthemums, and campanulas. Journal of Plant Physiology, 171, 1491-1499.

DOI: 10.1016/j.jplph.2014.06.012

Ryu, J.H., Seo, K.S., Choi, G.L., Rha, E.S., Lee, S.C., Choi, S.K., Kang, S.Y., Bae, C.H. (2012) Effects of LED Light Illumination on Germination, Growth and Anthocyanin Content of Dandelion (Taraxacum officinale). Korean Journal of Plant Research, 25 (6), 731-738. DOI: 10.7732/kjpr.2012.25.6.731

Sager, J.C., McFarlane, J.C. (1997) Radiation. U: Langhans, R.W., Tibbits, T.W., ur. Plant Growth Chamber Handbook. North Central Region Research Publication: lowa State University Press.

Stutte, G.W., Edney, S., Skeritt, T. (2009) Photoregulation of bioprotectant content of red leaves lettuce with lightemitting diodes. HortScience, 94, 79-92.

Vinković, T., Parađiković, N., Tkalec, M., Lisjak, M., Teklić, T., Zmaić, K., Vidaković, M. (2016) Utjecaj led osvjetljenja na prinos i parametre rasta rajčice. Poljoprivreda, 22 (1), 3-9. DÖ: 10.18047/poljo.22.1.1

\section{Influence of different type of artificial lighting on corn salad and garden cress seed germination}

\begin{abstract}
The aim of this research was to determine the influence of LED (light emitting diodes) and FLUO (fluorescent) lighting on seed germination and germination energy as well as on fresh weight and height of corn salad and garden cress seedlings. Seeding of natural seeds of corn salad and garden cress was done to Petri dishes, which were place in walk-in chamber equipped with LED and FLUO lamps. LED lamps had built-in blue $(440-460 \mathrm{~nm})$ and red $(650-670 \mathrm{~nm})$ diodes in 3:1 ratio. Research was carried out in Laboratory for vegetables, flowers, medicinal and spice herbs at Faculty of Agriculture in Osijek. Statistically significant influence of lighting type on corn salad seed germination energy and germination was determined where higher values were recorded in case of using LED lamps. On the contrary, corn salad seedlings fresh weight and height as well as garden cress seedling height where significantly higher when FLUO lamps where used as light source. However, lighting type did not significantly influenced on germination energy, germination and seedlings fresh weight of garden cress. Accordingly, it can be concluded that the plant responses on lighting type are species dependent form the very beginning of their growth and development.
\end{abstract}

Keywords: Valerianella locusta L., Lepidium sativum L., LED lamps, FLUO lamps, germination 